\section{Child psychiatry}

Dear Sirs

I write in response to Sebastian Kraemer's letter (Bulletin, October 1988).

Dr Kraemer asserts in his second sentence that "child psychiatry is by its very nature a multidisciplinary craft". This seems to me to be the accepted wisdom in child and adolescent psychiatry, but I am unaware of any evidence to support this assertion.

If the assertion of the multi-disciplinary nature of child and adolescent psychiatry is accepted, it follows that the practice of child and adolescent psychiatry should be carried out in multi-disciplinary teams. Of course this has enormous implications which have been debated to some extent but which seem to have been accepted by the profession without supporting evidence.

I would welcome a return to a public debate within the profession on this issue.

Deeside Child \& Adolescent Service

T. J. DYER Deeside, Clwyd

\section{Music therapy and mental health}

\section{DeAR SIRS}

The use of music in psychiatry is nothing new, with a history stretching back to early Arabic-Hebraic medical traditions. What is becoming a late 20 th century phenomenon is the specific application of music therapy in mental health services. Music therapists are beginning to explore music's functions above those of a general cultural, entertaining, relaxing and aesthetic nature.

Within Great Britain a music therapist is a professional musician who has undergone further postgraduate training in music therapy. Once qualified a music therapist can apply for membership of the professional association and work within the Whitley Council's established career and grading structure. Much emphasis is placed on active music-making, with clients being encouraged to create or listen to live music, music of a wide range of styles and traditions. Much use is made of free improvisation as a personal and self-expressive articulation of feelings, music being able to arouse deep emotional responses in us all. Tuned and un-tuned percussion is widely used, including instruments of African or Eastern origin. There is no typical session but a common pattern is a warm-up period-possibly involving listening to sounds, exploring instruments or group rhythmic individual/group issues explored musically. The session may then conclude with some form of summing-up and closure. Individual and group sessions take place with the music therapist adapting the music and style of leadership in relation to the needs of different clients and contexts. Musical skill is not a referral pre-requisite. Referrals are made across the whole age range and work occurs in the acute, rehabilitation and long-term areas.

One of the most commonly stated attributes of music therapy is its socialising nature. Inter-personal dynamics can be explored in an environment and within structures where the pressure is very much off verbal expression. Although there is no clear psychodynamic meaning of music, several therapists do relate aspects of musical processes to psychoanalytical theory. Several music therapists have undergone a personal analysis themselves or are involved in some form of individual or group psychotherapy. Other therapists may model their work on an eclectic or humanistic approach.

Recent research is developing ways of evaluating the effects of the work. Odell (1988), in her work with the elderly mentally ill at Fulbourn Hospital, Cambridge, compared levels of engagement between a verbal group and a music therapy group. Her results, although not significant, indicated higher levels of engagement in the music group. There was a significant increase when the results of regular weekly music therapy were compared with intermittent sessions. Since 1984 a series of projects has been set up in Bristol with funding from the Emperor Fine Arts Ltd, London. The aim of these projects is to discover how music therapy can be beneficial to people suffering from schizophrenia in particular. A project at Glenside Hospital, Bristol (1986) highlighted such specific effects as a high level of attendance, a high percentage of 'on-task' behaviour and increases in attention. More general effects such as a reduction in the level of tension as manifested in body posture were observed. As with Odell's work, the engagement and motivational aspects of music were highlighted in this project. The setting-up of a halfweek post at this hospital resulted from this project's very basic conclusions.

In addition to further quantitative results, more qualitative data are emerging from a project at a smaller Bristol day hospital facility (Bunt, Pike \& Wren, 1987). An initial questionnaire clearly indicated music therapy's contribution to changes in mood with a very high proportion of positive as compared to negative comments from both clients and staff. The work has also been the focus of two thirdyear psychology projects from Bristol University, when details of the social interactions and comparisons of musical and verbal content of the groups have been analysed. We are presently exploring further evaluation methods including client self-reporting. As this work continues we are finding out more about general effects and the detailed processes of the therapy. Eventually music therapy may be at the stage when it will have its own methodology and be 
regarded as a discipline in its own right. Until that time I would like to conclude that music therapy can contribute its own unique strengths as an adjunctive therapy working alongside other therapeutic interventions. Finally here is a client's general comment after an initial 10-week period of sessions.

"For me Music Therapy has provided an alternative avenue to the areas of my personality ... closed off, mainly through fear of disapproval. ... Group therapy, art therapy and music therapy have each provided contributions to reestablish a true self image."

Research Associate in Child and Mental Health. University of Bristol

Chairman: British Society for Music Therapy

\section{References}

Bristol Music THERAPY CENTRE (1986) Music Therapy in Psychiatry. Proceedings of a conference held at Glenside Hospital, Bristol - obtainable from the author.

Bunt, L., PIKE, A. \& WREN, V. (1987) Music therapy in a general hospital's psychiatic unit - a 'pilot' evaluation of an eight week programme. Journal of British Music Therapy, 1, 22-27.

ODELL, H. (1988) A music therapy approach in mental health. Psychology of Music, 16, 52-61.

'The Power of Music'. BBC Documentary, shown on 26 October 1988.

\section{Books for underdeveloped countries}

\section{DeAr Sirs}

With reference to the appeal for old journals (Bulletin, 12, 457), may I take the opportunity of drawing your readers' attention to the Ranfurly Library Service?

The Ranfurly is a registered charity which supplies books to libraries in third-world countries. Although originally established to support school libraries, it now supplies libraries at all levels - schools, hospital, universities and national collections. Books of all kinds are always in demand - children's books, fiction (especially "Eng. Lit."), textbooks (but not out-of-date scientific or legal texts), complete runs of recent scientific journals, reference books, large-print books, etc.

The Ranfurly Library Service is based at 39 Coldharbour Lane, London SE5 9NR (telephone 01-733 3577). As this is just around the corner from the Institute of Psychiatry I am acting as the University of London receiver for them - any parcels of books sent to me at the Institute will be faithfully forwarded. Projects supported recently by donations from within London University include the complete restocking of a School of Librarianship in Uganda, building up the stock of a medical school library in
Bangladesh and the provision of books to schools in refugee camps in the Lebanon.

The Ranfurly receives support from the Rotary. Readers from outside London may find that the easiest way to get parcels of books to libraries in underdeveloped countries is to contact their local branch of the Rotary.

Any assistance which your readers can give to this worthwhile cause will be warmly appreciated.

MARTIN GUHA

Librarian,

Institute of Psychiatry

De Crespigny Park

Denmark Hill

London SE5 8AF

\section{Difficulties of post membership registrars}

\section{DeAR Sirs}

The Collegiate Trainees Committee (CTC) is once again looking at the problems and difficulties faced by post membership registrars. May I approach such registrars through the letters columns of the Psychiatric Bulletin to contact me in order to enable us to identify the areas of difficulty as well as map out ways of changing those areas. All registrars who have passed their membership examinations a year or more ago and have not yet got senior registrar jobs are invited to contact me at the address below. They will be asked to fill in a short questionnaire, the data from which would then be used for the working party report.

DiNESH BHUGRA Convenor

CTC Working Party on Post Membership Registrars

The Maudsley Hospital

Denmark Hill

London SE5 8AZ.

\section{Job sharing}

\section{DeAR Sirs}

We are doing a job-share as locum senior registrar in adult psychiatry at the Westminster Hospital. The consultant in charge of the rotation here is keen to create a permanent job share on the scheme, but needs to know if this could be as competitive as all other appointments. Would anybody who would apply for such a post if it were advertised please contact us in order that we can prove this?

Diana Cassell

Gordon Hospital

Rosalyn Coleman

Bloomburg Street

London SWIV 2RH 